\title{
A CRIAÇÃO DA ESCOLA A PARTIR DA DIVISÃO SOCIAL DO TRABALHO
}

\section{THE CREATION OF THE SCHOOL FROM THE SOCIAL DIVISION OF WORK}

\author{
Lucia Mara de Lima Padilha ${ }^{1}$
}

\begin{abstract}
RESUMO
Até a divisão da sociedade em classes antagônicas a educação nas sociedades primitivas acontecia naturalmente; as crianças imitavam e reproduziam os atos realizados pelos adultos em suas atividades rotineiras. A partir dessa divisão a instrução se divide e a escola passa a atender a classe de proprietários de forma diferenciada daquela dos que nada possuem. Criada na antiguidade, essa escola desempenhou um importante papel na propagação das desigualdades sociais, uma vez que com a transformação da sociedade a educação passa a ter fins e objetivos definidos, elaborados pela classe dominante com vistas a garantir sua posição na sociedade.
\end{abstract}

\begin{abstract}
Until the division of society into antagonistic classes, education in primitive societies followed a natural course; children imitated and reproduced the acts performed by adults in their daily activities such as fishing and hunting. It was from the division of society into antagonistic classes that schooling divided itself and starts to attend in different ways people from different classes. Created in antiquity this form of school played an important role in the maintenance of social inequality, as with the transformation of society education starts to have defined purposes and objectives, elaborated by the dominant classes aiming at ensuring their position in society.
\end{abstract}

\section{A educação na sociedade primitiva}

Nas sociedades primitivas, denominadas tribais, o homem vivia em comunidade assentada sobre a propriedade comum da terra e unida por laços de sangue. Segundo Ponce (1963, p. 15), “[...] os seus membros eram indivíduos livres, com direitos iguais. O que era produzido em comum era repartido com todos, e imediatamente consumido". A educação acontecia naturalmente, as crianças imitavam e reproduziam os atos realizados pelos adultos em suas atividades rotineiras como a pesca e a caça.

O período primitivo é marcado por lentas e diferenciadas transformações nas formas de trabalho e no emprego da terra para a agricultura, utilizada para o plantio e também para o pastoreio. Esse desenvolvimento, acrescido da utilização do trabalho animal, da criação da roda e do transporte marítimo, trouxe consigo a produção excedente dos bens materiais. E “"...] tão cedo o bem-estar da tribo aumentou, por causa das novas técnicas de produção, os prisioneiros

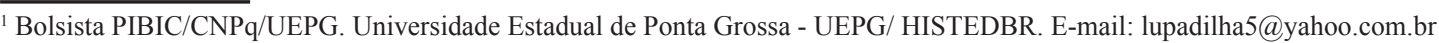


de guerra passaram a ser desejados ${ }^{2}$, e o inimigo vencido passou a ter sua vida garantida com a condição de transformar-se em escravo" (PONCE, 1963, p. 23, grifos do autor).

A sociedade, até então homogênea, passa a dividir-se em classes antagônicas; a propriedade, bem comum de todos os membros da tribo, passa a ser privada, propiciando assim a divisão da humanidade.

A transformação estrutural que originou a divisão da sociedade em classes e o estabelecimento da propriedade privada trouxe consigo consequências para o modo de vida do ser humano. A família primitiva baseada no matriarcado ${ }^{3}$ se modifica, e o homem, com o intuito de garantir que seus bens fossem herdados por seus filhos de sangue, passa a ocupar o lugar de soberano ${ }^{4}$ da casa. A mulher "[...] foi relegada a um segundo plano, passando a ocupar-se tão somente com funções domésticas, que deixaram de ser sociais" (PONCE, 1963 p.29, grifos do autor).

Desse modo, o trabalho realizado pela mulher, em sua família, "[...] perdia agora sua importância, comparado com o trabalho produtivo do homem; este trabalho passou a ser tudo; aquele, uma insignificante contribuição" (ENGELS, 1991 p.182). Vale acentuar que "[...] a divisão do trabalho e propriedade privada são expressões idênticas: a primeira enuncia em relação à atividade, aquilo que se enuncia na segunda em relação ao produto da atividade" (MARX; ENGELS, 1979, p.46).

A religião, a educação e a separação entre os trabalhadores braçais e os "intelectuais", até então inexistentes, se afirmam nesse contexto. $\mathrm{O}$ anseio da classe dominante pela conquista de riquezas e poder carece de uma instituição que a defenda e legitime seus direitos de exploração. Surge, então, o representante dessa classe, o Estado ${ }^{6}$, o qual, situado aparentemen-

\footnotetext{
${ }^{2}$ Com a escassa produção de alimentos as tribos vencidas num confronto eram saqueadas e seus moradores mortos. A partir da produção excedente de alimentos e a falta de mão-de-obra, essa concepção mudou.

${ }^{3} \mathrm{O}$ matriarcado na sociedade primitiva se dava por meio do matrimônio grupal, no qual a paternidade não podia ser estabelecida, sendo então a filiação instituída pela linha materna. Com a divisão de classes e o aumento das riquezas a família passa a ser monógama e patriarcal.

4 "Para assegurar a fidelidade da mulher e, por conseguinte, a paternidade dos filhos, aquela é entregue, sem reservas, ao poder do homem; quando este a mata, não faz mais do que exercer o seu direito" (ENGELS, 1991 p. 62).

5 "Intelectuais" no sentido de serem mais instruídos do que a maioria das pessoas.

${ }^{6} \mathrm{O}$ Estado nasce diretamente e fundamentalmente dos antagonismos de classes que se desenvolviam no seio mesmo da sociedade gentílica. Não é um poder imposto à sociedade "[...] de fora para dentro; é antes um produto da sociedade, quando esta chega a um determinado grau de desenvolvimento. É a confissão de que essa sociedade se enredou numa irremediável contradição
}

te por cima das classes em luta, deveria suprimir os conflitos abertos dessas classes e só permitir a sua luta no campo econômico, numa forma considerada legal (ENGELS, 1991).

Como consequência da divisão do trabalho, a educação, que até então acontecia de forma espontânea, passa a ter objetivos definidos, sendo destinada apenas para a classe dominante, pois, não tendo responsabilidades com o trabalho braçal, essa classe dispunha de tempo livre para realizar atividades de lazer. "E é aí que se localiza a origem da escola. [...] como se sabe, deriva do grego e significa, etimologicamente, o lugar do ócio" (SAVIANI, 2007, p.9).

Cabe ressaltar que a educação, na antiguidade, era estritamente privada, destinada apenas aos homens livres $^{7}$ que dispusessem de bens para pagá-la; e o poder sobre a educação nas cidades gregas e romanas, apesar de suas particularidades, estava nas mãos do Estado.

A escola criada na antiguidade desempenhou um importante papel na propagação das desigualdades sociais, uma vez que,

No momento da história humana em que se efetua a transformação da sociedade comunista primitiva em sociedade dividida em classes, e educação tem como fins específicos a luta contra as tradições do comunismo tribal, a incalcução da idéia de que as classes dominantes só pretendem assegurar a vida das dominadas, e a vigilância atenta para extirpar e corrigir qualquer movimento de protesto da parte dos oprimidos (PONCE, 1963, p.34).

A educação, antes um bem comum, com o surgimento das classes

[...] se divide entre aquela destinada aos não proprietários e aquela destinada aos proprietários. Os primeiros continuam a se educar no próprio processo de trabalho, fora da escola. Os segundos terão uma educação diferenciada, desenvolvida nas escolas, fora do trabalho, embora igualmente determinada pelo trabalho, já que é este que garantia a sua existência permitindo o desfrute do ócio, de tempo livre (SAVIANI, 2005 p.248).

com ela própria e está dividida por antagonismos irreconciliáveis que não consegue conjurar" (ENGELS, 1991 p.191).

${ }^{7}$ Entende-se por homens livres os cidadãos de Atenas pertencentes a uma aristocracia composta por grandes proprietários rurais. Sendo a cidadania um privilégio que se adquiria pelo nascimento, somente aos filhos de pai e mãe atenienses se reservava o direito de serem cidadãos, ficando de fora os estrangeiros e seus descendentes, que formavam a classe dos excluídos, os chamados metecos, assim como os escravos. 
A ruptura do escravismo para a ascensão da servidão se dá na Idade $\mathrm{Média}^{8}$, visto que para os grandes proprietários de terras a servidão passa a ser vista como uma grande vantagem sobre o trabalho escravo, uma vez que

[...] era necessário um grande capital para adquirir e manter os escravos necessários, ao passo que a servidão não requeria gasto: o servo custeava a sua própria vida, e todas as vicissitudes do trabalho corriam por sua conta. A servidão constituía, pois, a única maneira de que o patrão dispunha para tirar proveitos dos seus fundos, ao mesmo tempo em que também constituía o único modo dos que não possuíam terras proverem o seu próprio sustento (PONCE, 1963, p.81).

O cultivo de extensas áreas de produção deixa de ser lucrativo, passando a ser realizado pelos camponeses, arrendatários ou servos, em pequenas propriedades privadas.

As mudanças ocorreram também no âmbito da educação, que passa a ser estritamente religiosa sob o poder do cristianismo da Igreja Católica, que se constitui numa espécie de Estado9. Segundo Marrou (1975, p. 512), "[...] a partir do momento em que as escolas profanas, herdadas da Antigüidade, acabaram de desaparecer, essas escolas religiosas tornam-se o único instrumento através do qual se adquire e transmite a cultura".

A Igreja procurou desenvolver uma ação educativa sobre a comunidade, com o intuito de aumentar “[...] cada vez mais o poder civil, primeiro ligando-se a ele, depois tomando o seu lugar e fazendo o papel de reguladora formativa e administrativa" (CAMBI, 1999, p.126). O acesso às escolas católicas de formação monástica era restrito à aristocracia dominante, que dispunha de bens para pagar os estudos de seus

\footnotetext{
${ }^{8}$ A Idade Média não pode ser confundida apenas como a época entre dois períodos de desenvolvimento da civilização: o mundo antigo e o mundo moderno. Foi “[...], sobretudo a época da formação da Europa cristã e da gestão dos pré-requisitos do homem moderno (formação da consciência individual; do empenho produtivo; da identidade supranacional)" (CAMBI, 1999, p. 142).

9 "No dualismo Estado/Igreja, o poder imperial e os seus cuidados pelas escolas ficaram enfraquecidos, mas os aspectos administrativo-culturais do domínio ficaram em parte nas mãos de romanos, organizados em sua igreja. E é justamente por obra da igreja, como parte de suas atividades específicas, que cultura e escola se reorganizam. Não é por acaso que muitos bispos foram antes funcionários romanos dos reis bárbaros. E considerando que a igreja já tem uma dupla estrutura organizacional, isto é, vivendo ela em parte no meio do povo através dos bispados e das paróquias (clero secular), e em parte longe dele nos mosteiros (clero regular), é nessa dupla estrutura eclesial que devemos procurar os primeiros testemunhos do surgimento de novas iniciativas da educação cristã” (MANACORDA, 1996, p.114).
}

filhos. Para o restante da população era destinada uma educação alienante: "Não se ensinava a ler, nem a escrever, a finalidade dessas escolas não era instruir a plebe, mas familiarizar as massas campesinas com as doutrinas cristãs e, ao mesmo tempo, mantê-las dóceis e conformadas" (PONCE, 1963, p.87).

Como se viu, a educação propiciada pelas escolas católicas era uma iniciação dogmática destinada à classe que representava a nobreza, pois apenas os filhos dos nobres poderiam ter acesso à escolaridade, enquanto que a maioria da população continuava analfabeta.

As mudanças econômicas e sociais ocorridas durante a Idade Média propiciaram o aparecimento de uma nova classe social ${ }^{10}$ formada por comerciantes, a qual transforma as cidades e, sem participar da produção,

[...] conquista a direção geral da mesma e avassala economicamente os produtores; uma classe que se transforma no intermediário indispensável entre dois produtores, e os explora a ambos. Sob o pretexto de poupar aos produtores as fadigas e os riscos da troca de produtos, de encontrar saída para os produtos até nos mercados mais distantes, tornando-se assim a classe mais útil da sociedade, forma-se uma classe de aproveitadores, uma classe de verdadeiros parasitas sociais, que, em compensação por seus serviços, na realidade insignificantes, retira a nata da produção nacional e estrangeira, concentra rapidamente em suas mãos riquezas enormes e adquire uma influência social correspondente a estas, ocupando, por isso mesmo, no decurso desse período de civilização, posição de mais e mais destaque, logrando um domínio sempre maior sobre a produção, até gerar um produto próprio: as crises comerciais periódicas (ENGELS, 1991, p.186).

\footnotetext{
${ }^{10}$ As origens da nova classe social que começou a se formar durante a Idade Média são um pouco obscuras, mas sabemos que ela apareceu no próprio momento em que uma importante transformação econômica abalou as próprias bases do feudalismo. Até o século X, as cidades não passavam de miseráveis vilas. Os seus habitantes se resumiam a uns poucos artesãos e domésticos, que trabalhavam para o senhor feudal sob as mesmas condições que eram impostas aos servos da gleba. Mas, a partir do século XI, progressivas modificações técnicas provocaram um florescimento do comércio. Até esse momento, o senhor feudal, que era dono da cidade, ou burgo, só tinha que comprar uns poucos objetos de luxo, provenientes do Oriente. Os camponeses dos seus domínios lhe traziam alimentos e as matérias primas, que os artesãos da cidade trabalhavam. Mas tão logo entrou em circulação o dinheiro, o senhor feudal achou vantajoso permitir que seus artesãos - mediante retribuição econômica - passassem a trabalhar para terceiros, ao mesmo tempo em que achou interessante permitir a entrada de mercadorias nos seus castelos. E, assim, " [...] as cidades se transformaram em centros de comércio, onde os produtores trocavam os seus produtos. Surgiu, então, uma profunda transformação: o que até ontem era apenas uma fortaleza, começava agora a ser um mercado." (PONCE, 1963, p. 9, grifos do autor).
} 
Essas mudanças refletiram-se diretamente na educação. As escolas monásticas, localizadas em lugares de difícil acesso, já não atendiam às necessidades da nova classe emergente. A burguesia reclamava por escolas criadas nas cidades, uma vez que o comércio em desenvolvimento exigia um novo tipo de instrução. Surge então a Universidade, cuja fundação "[...] permitiu que a burguesia participasse de muitas vantagens da nobreza e do clero, que até então lhe tinham sido negadas. [...] A conquista de um título universitário elevava o burguês quase ao nível da nobreza" (PONCE, 1963,p. 97)

No entanto, a conquista da burguesia não significou que as massas populares tiveram acesso à educação, mesmo com a criação das escolas primárias administradas e custeadas pelas cidades ${ }^{11}$. E como "[...] para a igreja e para o senhor feudal a escola nunca significou ilustração popular, também para a burguesia, pelo menos nesse momento histórico, ela não tinha esse sentido" (PONCE, 1963, p.101).

Uma série de fatores propiciou o fim da Idade Média e a chegada do Renascimento, dentre eles o fortalecimento da burguesia, cujo próposito era o de ter mais governabilidade que as autoridades que reinavam na época. Com isso, intensifica-se o comércio, surge um tipo de monarquia nacional, o aumento do crescimento urbano e as viagens marítimas que partem para novos descobrimentos, anunciando assim a falência do feudalismo.

O Renascimento caracterizou-se como um movimento de muitas mudanças na literatura, nas artes e também na filosofia, sendo inicialmente difundido na Europa, principalmente nos países ligados ao comércio. Foi fortemente demarcado através de um homem valorizado, humanizado, o que vai ao desencontro do pensamento medieval em que o divino ou o sobrenatural eram conceitos importantes na formação do homem. Na Idade Média, Deus era a figura central. A partir do Renascimento, quando o homem (burguês) passa a ser o centro, com valores considerados modernos, o humanismo é visto como elemento central.

Percebe-se que, apesar de todas as modificações conjunturais ocorridas durante o processo de desenvolvimento da sociedade primitiva até o surgimento

\footnotetext{
${ }^{11} \mathrm{O}$ ensino ministrado nas escolas municipais já estava menos divorciado das necessidades práticas da vida, [...]. Mas, não se pense que as escolas municipais fossem gratuitas: apesar de o município pagar certo estipêndio aos professores - soldos de fome, naturalmente - os alunos deviam pagar diretamente os professores pelos seus ensinamentos, e esse pagamento era proporcional às dificuldades das matérias ensinadas. (PONCE, 1963, p.100).
}

da classe burguesa, a estrutura baseada na diferença das classes não se modifica. E a educação correlata ao "[...] processo de surgimento da sociedade de classes que, por sua vez, tem a ver com o processo de aprofundamento da divisão do trabalho" (SAVIANI, 2007, p.9), continua a ser destinada apenas àqueles que detêm o poder econômico nas mãos.

\section{A escola pública e gratuita}

Os primeiros discursos a favor de uma escola estatal e pública têm sua origem no século XVIII, na Alemanha, mais precisamente na Prússia, num momento de grandes transformações, visto que é o século das luzes, do esclarecimento, da vontade livre, do pensamento e do conhecimento. "Politicamente, é o século do chamado 'despotismo esclarecido', da instrução do povo, mas sem povo, imposta de cima para baixo; da secularização da educação e de sua subordinação ao Estado" (LUZURIAGA, 1959, p.23).

O século XVIII é marcado pelo desenvolvimento do trabalho, que passa da manufatura para a indústria. A “[...] produção não é mais para o consumo pessoal e sim para a troca - os produtos passam necessariamente de umas para outras mãos. O produtor separa-se de seu produto na troca, e já não sabe o que é feito dele" (ENGELS, 1991, p.197).

Com o novo processo de transformação do trabalho - que antes era realizado no campo, pelos camponeses, e nas oficinas, pelos artesãos, e depois passa a ser realizado nas fábricas ou estabelecimentos industriais, tornando-se um trabalho industrial - a massa da população vai sendo incorporada nesta nova forma de trabalho, e o homem que estava no campo se desloca para as cidades. Isso provoca grandes conflitos sociais, pois com a expansão do comércio ocorreu "[...] a concentração das riquezas nas mãos de uma classe pouco numerosa, que se fez acompanhar do empobrecimento das massas e do aumento numérico dos pobres" (MARX; ENGELS, 1979, p.188).

Na fábrica o ex-camponês e o ex-artesão perdem sua identidade, seus aprendizados são descartados, e toda e qualquer instrução que possuíam não é mais aproveitada, surgindo então a necessidade de se oferecer uma nova instrução a esse operário, voltada, é claro, aos novos interesses do sistema produtivo da sociedade moderna. Sendo assim, os conhecimentos, 
[...] a sagacidade e a vontade desenvolvidas pelo camponês e artesão independentes no período manufatureiro "passam a ser exigidas apenas pela oficina em seu conjunto", desenvolvendo-se as forças intelectuais num sentido de unilateralidade, concentrando-se no capital em detrimento dos trabalhadores parciais: "a divisão manufatureira do trabalho opõe-lhes as forças intelectuais do processo material de produção como propriedade de outrem e como poder que os domina". Trata-se de um processo que começa na cooperação simples, "desenvolve-se na manufatura, que mutila o trabalhador, reduzindo-o a uma fração de si mesmo, e completa-se na indústria moderna que faz da ciência uma força produtiva independente de trabalho, recrutando-o para servir o capital" (MARX, 1968, p.413-414).

Com a revolução Industrial e, consequentemente, com o surgimento da sociedade capitalista a educação passa a ter outros fins, não mais só o da formação de intelectuais, mas também o da formação das massas, a qual deveria atender ao mercado de trabalho livre e assalariado, executado nas grandes fábricas, com o intuito de gerar maior lucratividade. Essa divisão do trabalho ocorrerá também na educação, “[...] porque aí se dá a possibilidade, a realidade de que a atividade espiritual e a atividade material, o prazer e o trabalho, a produção e o consumo se apliquem a indivíduos distintos" (MANACORDA, 1996, p. 46). Desse modo, a educação se volta para atender ao mercado, "[...] fábrica e escola nascem juntas: as leis que criaram a escola de Estado vêm juntas com as leis que suprimem a aprendizagem corporativa (e também da ordem dos jesuítas)" (Idem, p. 249).

A instituição escolar pública ${ }^{12}$ surge nesse contexto como resposta ao novo sistema capitalista, que exige uma nova forma universal de instrução, capaz de acompanhar o crescimento da ciência e da indústria moderna. Essa nova forma de instrução provocará mudanças " [...] na própria educação confessional e colocará em posição central o protagonismo do Estado, forjando a idéia da escola pública, universal, gratuita, leiga e obrigatória" (SAVIANI, 2007, p.12).

\footnotetext{
${ }^{12}$ A primeira metade do século XIX foi marcante para a educação pública, na Prússia. Houve a difusão geral da escola elementar, a melhoria na formação dos professores pela implantação de Escolas Normais, a renovação dos métodos e especialmente a formação de uma nova mística em relação à educação, sob o pressuposto de que as reformas sociais e políticas deveriam surgir pela educação. Pela reforma moral e intelectual do povo se chegaria a um novo processo de desenvolvimento (KREUTZ, 1985, p. 40).
}

\section{Conclusão}

A partir dos elementos expostos, conclui-se que a criação da escola, desde a sua gênese, é correlata à divisão social do trabalho, da instituição da propriedade privada e, consequentemente, da divisão da sociedade em classes. Criada para atender a uma determinada parcela da sociedade, percebeu-se que a escola, no transcorrer do processo histórico da humanidade, não fez mais que propagar as ideias da classe que detinha o poder nas mãos. Ao propor uma escola pública, gratuita e estatal, o Estado, como representante dessa classe, propôs ideologicamente uma educação democrática que atenderia a toda a população, sem distinção de classes. No entanto, seria impossível atender aos interesses de toda uma sociedade que estruturalmente está dividida em classes antagônicas, ou seja, burguesia e proletariado, ricos e pobres.

\section{Referências}

CAMBI, Franco. História da pedagogia. São Paulo: Editora UNESP, 1999.

ENGELS, Friedrich. A origem da família, da propriedade privada e do Estado. Tradução de Leandro Konder. 12. ed. Rio de Janeiro - RJ: Bertrand Brasil S.A, 1991.

KREUTZ, Lúcio. Magistério e imigração alemã: o professor paroquial católico teutobrasileiro do Rio Grande do Sul no movimento da restauração. Tese de doutorado. Pontifícia Universidade Católica, São Paulo, 1985.

LUZURIAGA, Lorenzo. História da educação pública. São Paulo: Companhia Editora Nacional, 1959.

MANACORDA, Mario Alighiero. História da educação: da antiguidade aos nossos dias. Tradução de Gaetano Lo Monaco; revisão da tradução Rosa dos Anjos Oliveira e Paolo Nosella. 5. ed. São Paulo: Cortez, 1996.

MARROU, Henri Irénée História da educação na antiguidade. Tradução de Mário Leôndidas Casanova. $4^{a}$ reimpressão. São Paulo: E.P.U.; Brasília: INL, 1975.

MARX, Karl; ENGELS, Friedrich. A ideologia alemã. 2. ed. São Paulo: Livraria Editora Ciências Humanas Ltda, 1979.

MARX, Karl. O capital. Livro 1, vol. I e II. Rio de Janeiro: Civilização Brasileira,1968.

PONCE, Aníbal. Educação e luta de classes. Tradução de José Severo de Camargo Pereira. São Paulo: Fulgor, 1963.

SAVIANI, Dermeval. A escola pública no Brasil: história e 
historiografia. In: LOMBARDI, José Claudinei; SAVIANI, Dermeval; NASCIMENTO, Maria Isabel Moura (Orgs.). A Escola Pública no Brasil: história e historiografia. Campinas, SP: Autores Associados: HISTEDBR, 2005. (Coleção Memória da Educação).

Instituições escolares no Brasil: conceito e reconstrução histórica In. NASCIMENTO, Isabel Moura. et al. (Orgs.). _ Campinas, SP: Autores Associados: HISTEDBR; Sorocaba, SP: Uniso; Ponta Grossa, PR: UEPG, 2007. - (Coleção Memória da Educação). 